\title{
Heat Stress Enhances Phytophthora Root Rot Severity in Container-grown Chrysanthemums
}

\author{
J.D. MacDonald' \\ Department of Plant Pathology, University of California, Davis, CA 95616 \\ Additional index words. Phytophthora cryptogea, Dendranthema $\times$ grandiflorum
}

\begin{abstract}
Cuttings of Dendranthema xgrandiflorum 'Paragon' were used as a model system to assess the effects of root heating on disease severity. Roots were exposed to single episodes of heat stress, after which they were inoculated with zoospores of Phytophthora cryptogea Pethyb. \& Laff. Root damage resulting from heat stress, or heat stress plus Phytophthora, was quantified 5 to 7 days after treatment. Roots of hydroponically grown plants, immersed for 30 min in aerated, temperature-controlled nutrient solutions, were severely damaged at $45 \mathrm{C}$ or above. Relatively little phytophthora root rot developed on inoculated plants exposed to 25 or $35 \mathrm{C}$, but infection was severe in roots heated to 40C. Plants grown in potting mix were exposed to heat stress by plastic-wrapping the containers in which they were growing and placing them in heated water baths until roots achieved desired temperatures for 30 min. This system heated roots more slowly than in the hydroponic experiments, and 45 and 50C were less damaging. The amount of Phytophthora-induced root damage was insignificant in containerized plants heated to 25 or $35 \mathrm{C}$, but was highly significant in those heated to $40 \mathrm{C}$ or higher. In field experiments, plants were positioned so their containers were either fully exposed to the late afternoon sun or heavily shaded to prevent sun exposure. The root zones of sunexposed pots heated to 45 to $47 \mathrm{C}$, while those of shaded pots never exceeded 34 to $36 \mathrm{C}$. There was a large, highly significant increase in phytophthora root rot severity in the sun-exposed pots compared to shaded plants. These experiments showed that temperatures of $40 \mathrm{C}$ or higher, which commonly occur in container-grown plants exposed to solar radiation, can predispose chrysanthemum roots to severe Phytophthora infection.
\end{abstract}

Heat injury to the roots of container-grown plants, caused by solar radiation on container walls, has been recognized as a problem in nurseries for many years. Root-zone temperatures near the sun-exposed walls of containers are much higher than infield soils (Fretz, 1971; Graves and Dana, 1987; Keever and Cobb, 1985; Verma,. 1979; Young and Hammett, 1980) and can result in root death or poor, uneven development of root systems (Barr and Pellett, 1972; Harris, 1967; Wong et al., 1971).

While portions of the root systems of container-grown plants are exposed occasionally to temperatures that are lethal, and commonly to temperatures that are stressful (Fretz, 1971; Keever and -Cobb, 1985; Verma, 1979; Young and Hammett, 1980), very little is known about how heat stress affects root-pathogen interactions. Other forms of root stress (e.g., low soil $\mathrm{O}_{2}$ or water status, or excess salinity) are known to predispose roots to Phytophthora infection (Blaker and MacDonald, 1981; Filmer et al., 1986; Heritage and Duniway, 1985; MacDonald, 1982, 1984; Swiecki and MacDonald, 1988; Wilcox and Mirectich, 1985), but the role of temperature in root diseases has generally been attributed to temperature optima for the growth of pathogens (Hine et al., 1964; Hine and Aragaki, 1963; Patil and Young, 1960).

In experiments that did explore the effects of heat stress on root-pathogen interactions, Chamberlain and Gerdemann (1966) reported that immersing soybean roots in a $44 \mathrm{C}$ water bath for 60 min caused some root injury and plant stunting, but no lasting damage. When plants were subsequently exposed to Phytophthora megasperma var. sojae, however, heat treatments caused normally resistant Harosoy 63 plants to become severely diseased. Heat stress also induced susceptibility to Phytophthora cactorum and Helminthosporium sativum, fungi that are not oth-

Received for publication 9 Apr. 1990. This work was supported in part by funds provided by the California Assn. of Nurserymen. I thank M. Beckwith and N. Blaker for technical assistance. The cost of publishing this paper was defrayed in part by the payment of page charges. Under postal regulations, this paper therefore must be hereby marked advertisement solely to indicate this fact.

'Associate Professor. erwise pathogenic to soybean. Increased susceptibility was reversible and was attributed to a temporary, heat-induced reduction of phytoalexin synthesis (Chamberlain, 1970; Chamberlain and Gerdemann, 1966). While clearly demonstrating that heat stress can predispose roots to pathogenic attack, the temperatures used by Chamberlain and Gerdemann (1966) are not typical of those encountered by roots of soybean or other field-grown plants (Graves and Dana, 1987). In addition, immersing roots in heated water baths does not accurately reflect heating patterns that occur in the root systems of container-grown plants (Young and Hammett, 1980). The purpose of this study, therefore, was to determine the impact of heat stress, within the range that would be typically encountered by container-grown plants, on development of phytophthora root rot of chrysanthemum.

\section{Materials and Methods}

Biological materials. Terminal cuttings of 'Paragon' chrysanthemum were rooted by suspending their cut ends over vigorously aerated half-strength Hoagland's solution (Hoagland and Arnon, 1950) until roots 2 to $4 \mathrm{~cm}$ long developed. Rooted cuttings were transferred to crocks of nutrient solution or pots containing UC mix potting medium (Matkin and Chandler, 1957). Plants were inoculated with an isolate of Phytophthora cryptogea Pethyb. \& Laff. pathogenic to chrysanthemum. Zoospore inoculum was prepared by cutting 7-mm-diameter disks of aerial mycelium from the surface of 7-day-old pea dextrose agar (MacDonald and Duniway, 1978a) colonies and incubating them at room temperature for 5 days in petri dishes of nonsterile soil extract (MacDonald, 1982). Numerous sporangia formed on the mycelial disks during incubation, and zoospore release was stimulated by chilling the soil extract to $12 \mathrm{C}$ for $1 \mathrm{~h}$, followed by rewarming to room temperature. Zoospores were separated from mycelial disks $1 \mathrm{~h}$ later by filtration through four layers of cheesecloth, and the concentration in the resulting suspension was determined with a hemacytometer.

Hydroponic culture. Initial experiments used hydroponically grown plants to enable comparison with earlier research (Chamberlain and Gerdemann, 1966). Three freshly rooted cuttings 
no significant difference in the amount of root necrosis between healthy and inoculated plants (Fig. 1). However, at 40C, there was a large, highly significant $(P<0.0001)$ increase in root necrosis in inoculated plants when compared to inoculated plants at lower temperatures or noninoculated plants at the same temperature (Fig. 1). The 40C exposure was assumed to have been stressful to roots, since those exposed to the $45 \mathrm{C}$ treatment became nearly completely necrotic in the absence of Phytophthora (Fig. 1).

The extensive root damage observed in noninoculated plants at $45 \mathrm{C}$ (pg. 1) suggested that the abrupt temperature changes inherent $\mathrm{m}$ the hydroponic experiments were particularly damaging to roots. In another experiment, roots were exposed to $45 \mathrm{C}$ for various lengths of time. By this method, it was found that a 20 -min immersion of roots in the $45 \mathrm{C}$ solution was sufficient to cause nearly complete root death (Fig. 2). However, a 10-min exposure' caused only light damage to roots and predisposed them to severe pathogenic attack (Fig. 2).

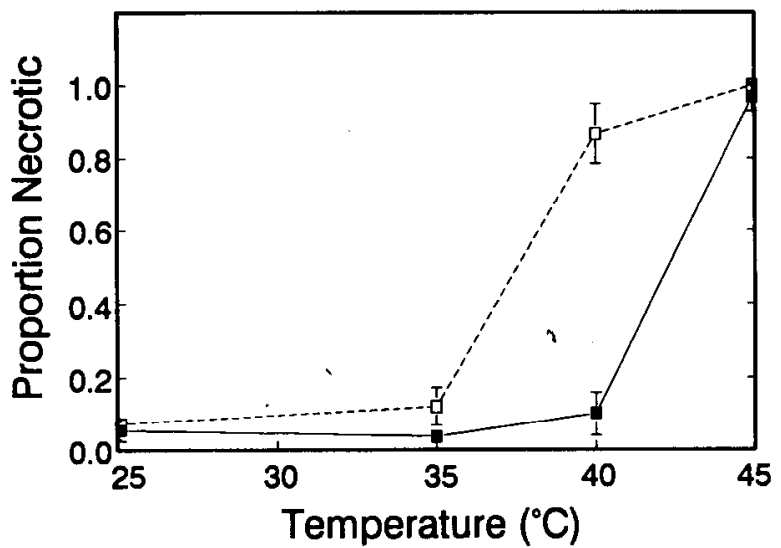

Fig. 1. Influence of temperature on the amount of root necrosis in hydroponically grown chrysanthemum cuttings. (罗) Roots that were not inoculated; ( $\square$ ) roots that were inoculated with $P$. cryptogea following heat exposure. Total root length and necrotic root length were determined 5 days after temperature and inoculation treatments. Each point represents the mean of six plants. Vertical bars represent \pm 1 SD.

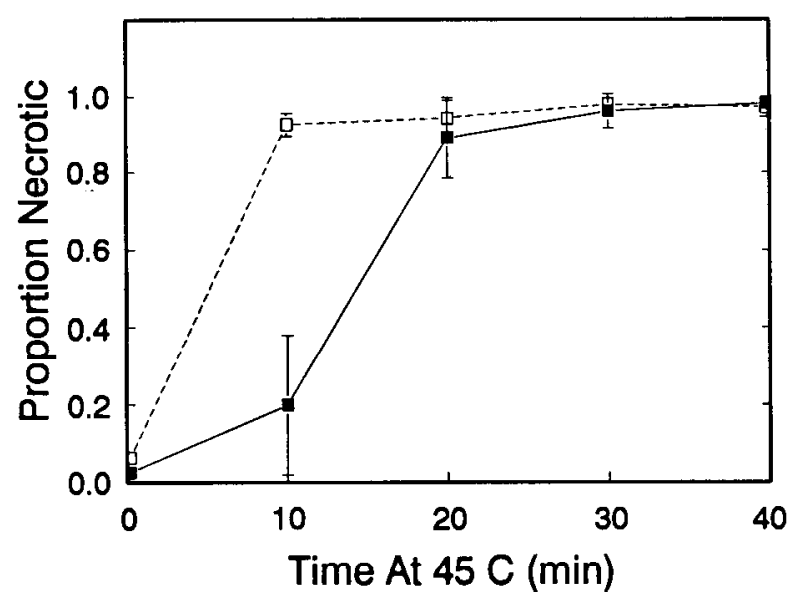

Fig. 2. Influence of time at $45 \mathrm{C}$ on the amount of root necrosis in hydroponically grown chrysanthemum cuttings. ( $\mathbf{\square}$ ) Roots that were not inoculated; $(\square)$ roots that were inoculated with $P$. cryptogea following heat exposure. Total root length and necrotic root length were determined 5 days after temperature and inoculation treatments. Each point represents the mean of six plants. Vertical bars represent \pm 1 SD.
Container-grown plants. In contrast to the hydroponic experiments, the roots of plants grown in containers of UC mix experienced more gradual temperature shifts when placed in the heated water baths. Thermocouples placed in the centers of the containers showed that it took 20 to $30 \mathrm{~min}$ for the root mass to nearly equilibrate to the water bath temperature (Fig. 3). Because plants were maintained at the desired temperature for $30 \mathrm{~min}$ after equilibration, their overall exposure to elevated temperatures was up to twice as long as plants in the hydroponic experiments. However, in spite of a longer exposure to elevated temperatures, the more-gradual heating resulted in substantially less heat injury to uninoculated roots at 45 to 50C (Figs. 1 and 4).

While the roots of container-grown plants had less heat injury at high temperatures than hydroponically grown plants, root damage still was significantly influenced by temperature, inoculation, and the interaction of these factors. Because the results from all four experiments with container-grown plants were very similar, the data were pooled for analysis.

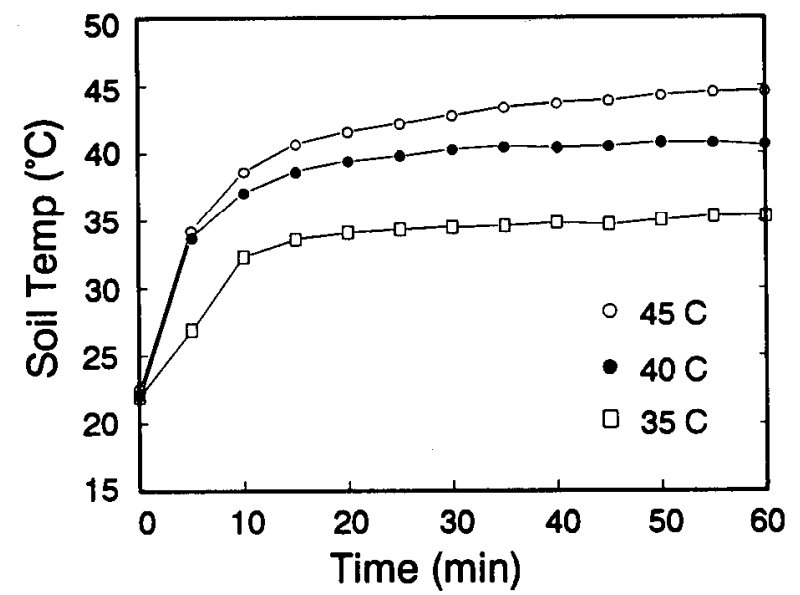

Fig. 3. Rate of heating in $4-\mathrm{cm}$-diameter $(0.25$ liter $)$ pots containing UC mix. Pots were placed in plastic bags before immersion in heated water baths to prevent infiltration of heated water into the potting medium. Thermocouples were placed in the center of the container, and temperatures were recorded with an Omnidata data logger.

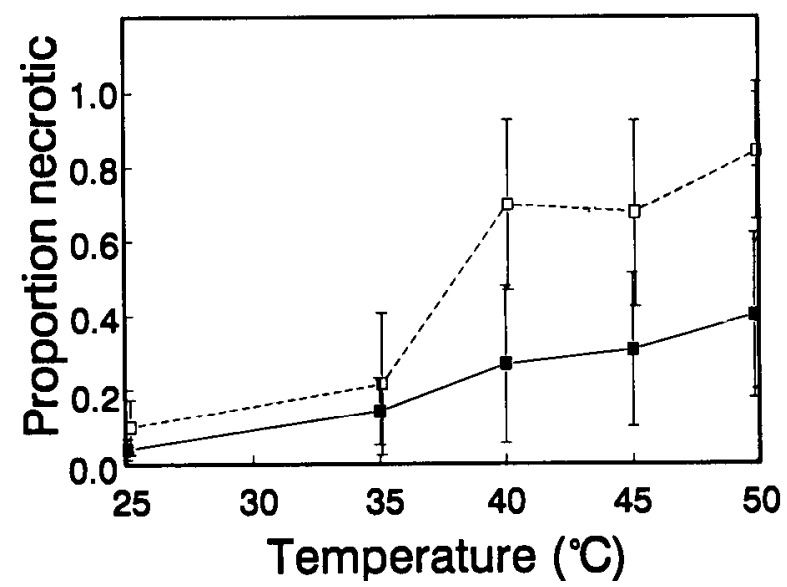

Fig. 4. Influence of temperature on the amount of root necrosis in soil-grown chrysanthemum cuttings. ( $\mathbf{a}$ ) Roots that were not inoculated; ( $\square$ ) roots that were inoculated with P. cryptogea following heat exposure. Total root length and necrotic root length were determined 5 days after temperature and inoculation treatments. Each point represents the mean of 18 to 22 plants. Vertical bars represent \pm 1 SD. 
In noninoculated plants, there was a progressive increase in root damage with increasing temperature (Fig. 4). At 35C, root damage w-as not significantly different from unheated (25C) control plants; at 40C or higher, damage increased significantly'. In plants inoculated with $P$. cryptogea, there was no significant increase in root damage at $35 \mathrm{C}$ relative to $25 \mathrm{C}$ (Fig. 4). Exposure to higher temperatures, however, did cause significant increases in root damage. When inoculated and noninoculated plants were compared at the same temperatures, a detectable, but nonsignificant, increase in root damage occurred at 25 and 35C. However, the interaction between inoculation and temperature-resulted in large, highly significant $(P<0.0001)$ increases in root damage at $40 \mathrm{C}$ or above (Fig. 4). Culture plate results showed that roots exposed to $\geq 40 \mathrm{C}$ were heavily colonized by $P$. cryptogea.

Field experiments. Thermocouples placed in the pots showed that root-zone temperatures in the sun-exposed and shaded pots peaked at $\approx 1730 \mathrm{HR}$. The maxima recorded were 45 to $47 \mathrm{C}$ and 34 to $36 \mathrm{C}$, respectively. Root temperatures in these experiments increased gradually over a period of several hours, a rate that was much slower than in the experiments with soil-grown plants immersed in water baths (Fig. 3). However, the results were very similar to those from the earlier experiments (Figs. 4 and 5).

In the absence of heat stress, $P$. cryptogea caused a detectable, but nonsignificant, increase in root damage (Fig. 5). In the absence of $P$. cryptogea, exposure of the roots to 45 to $47 \mathrm{C}$ led to a significant increase in root damage relative to noninoculated roots at 34 to $36 \mathrm{C}$. But the most severe damage to roots occurred when they were exposed to P. cryptogea following this single episode of heat stress. Damage to roots caused by temperature, inoculation, and the interaction of these variables was, again, highly significant $(P<0.001)$, and culture plate results again confirmed extensive colonization of heatstressed roots by $P$. cryptogea,

Field measurements showed that temperatures in fully exposed containers rose above 40C twice in the course of a day. At the east wall of the container, temperatures increased rapidly from 0800 to $1000 \mathrm{HR}$ and. peaked around noon (Fig. 6A). On the west wall of the container, temperatures increased gradually

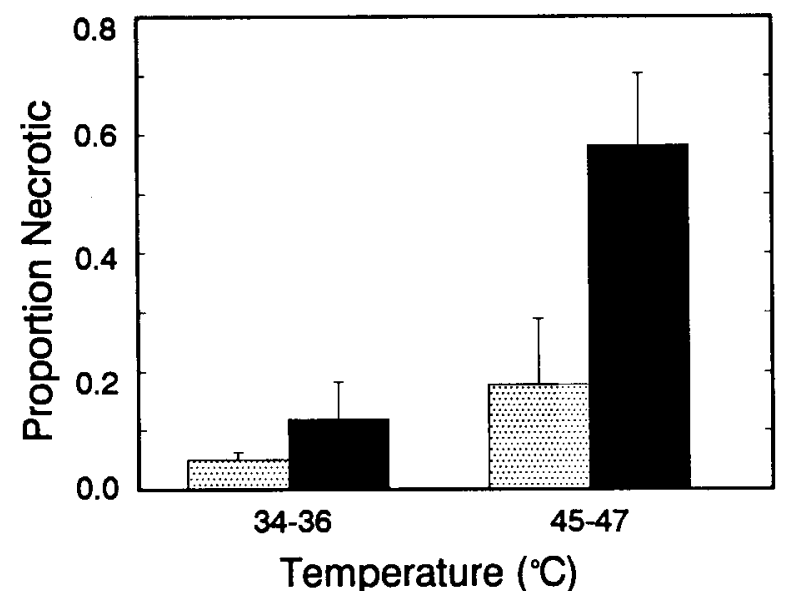

Fig. 5. Influence of high root-zone temperatures, induced by a single exposure of containers to solar radiation, on the amount of root necrosis in soil-grown chrysanthemum cuttings. Total root length and necrotic root length were determined 5 days after sun exposure and inoculation treatments. Solid bars represent plants inoculated after sun exposure, shaded bars represent noninoculated plants. Values are the means of five plants; vertical lines indicate $\pm 1 \mathrm{SD}$.
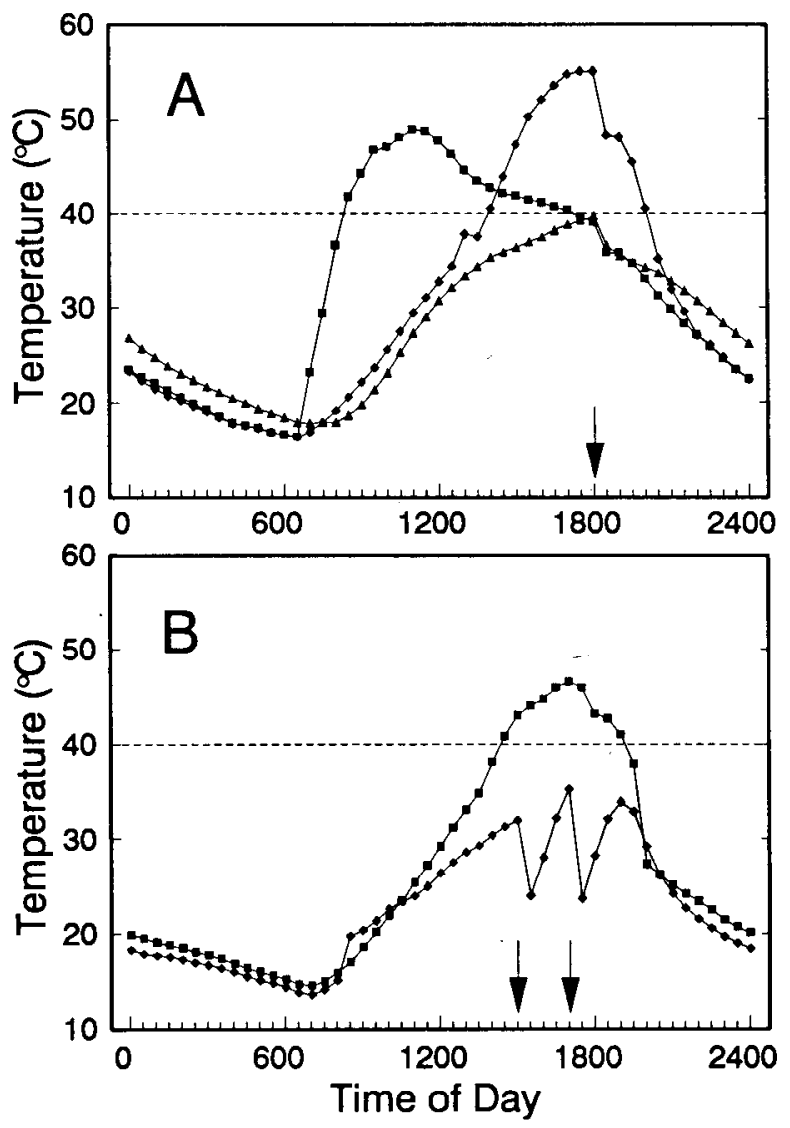

Fig. 6. Daily temperature cycles in sun-exposed containers. Thermocouples were placed in 7.5-liter pots in which 2-year-old Juniperus chinensis 'Prince of Wales' plants were growing. Temperatures were recorded every 30 min using an Omnidata data logger. Graphs show typical midsummer temperature cycles, and arrows show irrigations. (A) Temperatures at the east wall ( $\boldsymbol{\square})$, west wall ( $\bullet$ ), and center ( $\boldsymbol{\Delta}$ ) of a container on a day when air temperature peaked at $40 \mathrm{C}$ at $1400 \mathrm{HR}$. (B) Temperatures at the west wall of a container irrigated lightly at $1700 \mathrm{HR}(\boldsymbol{\square})$ or heavily at 1500 and $1700 \mathrm{HR}(\bullet)$ on a day when air temperature peaked at $37 \mathrm{C}$ at $1430 \mathrm{HR}$.

throughout the day and peaked near 1800 HR. Temperature in the center of the pot also peaked at $1800 \mathrm{HR}$, but never rose above $40 \mathrm{C}$, even when temperatures at the west wall were in excess of 55C (Fig. 6A). A distinct drop in temperature was noted at all positions by $1830 \mathrm{HR}$ (Fig. 6A). This drop coincided with the single, daily irrigation. In experiments where two irrigations were applied at 1500 and $1700 \mathrm{HR}$, sharp temperature drops were noted (Fig. 6B). Temperature at the west wall of these containers never exceeded $35 \mathrm{C}$, while temperatures in containers receiving a single, nightly irrigation exceeded 40C for $\approx 5 \mathrm{~h}$ (Fig. 6B).

\section{Discussion}

These experiments showed that chrysanthemum roots exposed to temperatures $40 \mathrm{C}$ are predisposed to severe infection by $P$. cryptogea. Although treatment effects were quantified by visual measurements of root necrosis, culture plate results indicated that the increased necrosis observed in heat-stressed, inoculated plants (Figs. 1, 2, 4, and 5) was associated with extensive fungal colonization.

The immersion of exposed roots in $\geq 45 \mathrm{C}$ nutrient solutions was very damaging, with exposure times as short as $20 \mathrm{~min}$ causing virtually complete necrosis of root systems (Fig. 2). 
This contrasts with soybean and Fraser fir roots, which were not damaged by immersion in 45C water baths for 60 or 120 rein, respectively (Benson, 1978; Chamberlain and Gerdemann, 1966). Chrysanthemum roots were predisposed to extensive invasion by $P$. cryptogea at temperatures they could tolerate without direct heat injury (40C for 30 minor $45 \mathrm{C}$ for $10 \mathrm{~min}$ ) (Figs. 1 and 2). In this sense, the results were similar to those reported for soybean, where roots exposed to $44 \mathrm{C}$, which was nonlethal, were predisposed to infection by several fungi (Chamberlain and Gerdemann, 1966).

Relative to the hydroponic experiments, roots exposed to $\geq 45 \mathrm{C}$ while growing in a potting mix were not severely damaged (Figs. 4 and 5). For example, $30 \mathrm{~min}$ at 45C caused 100\% root necrosis in hydroponic experiments (Figs. 1 and 2), but damaged only. $\approx 30 \%$ of the total root length of potting mix-grown plants (Fig. 4). Also, potted plants exposed to a maximum of 45 to $47 \mathrm{C}$ for $\approx 60 \mathrm{~min}$ in the field had $<20 \%$ of their root length damaged (Fig. 5). The smaller amounts of direct heat injury observed in experiments with soil-grown plants were probably due to moderating effects of the potting medium. The mass of the potting medium absorbed heat, which slowed the rate of root heating (Figs. 3 and 6), and heat conduction to the roots was probably less efficient in the potting medium due to the presence of air-filled pores.

The amount of root damage in noninoculated field-grown plants was less than expected, based on the laboratory experiments (Fig. 4). However, the containers used in the field experiments were larger, and the radial spread of roots caused some to grow toward the center of the pot. When the plants were placed in the field, the pot centers did not heat to the same extent as the sun-exposed walls. Thus, roots in the field experiment were not as uniformly heated as those in the laboratory experiments and showed less overall injury.

The data from the hydroponic and container-grown plant experiments (Figs. 1 and 4) suggest that 40C represents a critical stress threshold in chrysanthemum. The mechanisms underlying heat stress predisposition are unknown but could involve several factors. In soybean, heat stress predisposition was attributed to reduced phytoalexin synthesis, which allowed infection by fungi not typically pathogenic to soybean (Chamberlain and Gerdemann, 1966). There is no evidence of phytoalexin synthesis in chrysanthemum roots, but Phytophthora infection of unstressed plants does induce defense responses, including rapid cell necrosis, formation of papilli, and tissue Signification (Swiecki and MacDonald, 1988). The physiological processes underlying these responses could be disrupted by heat stress. Another factor that could be involved is altered pathogen behavior in the presence of heat-stressed roots. Heat stress adversely affects membrane function (Raison et al., 1980) and has been shown to significantly increase root exudation (Ingram and Buchanan, 1981). This result could influence zoospore chemotaxis and cause more zoospores to be attracted to heat-stressed roots in the same way they are attracted to salt-stressed roots (MacDonald, 1982).

The temperatures that predispose roots to infection are in a range also known to adversely affect Phytophthora. For example, sporangia of P. cryptogea have been reported to undergo a steady decline in their capacity to release zoospores with prolonged exposure to 36C (MacDonald and Duniway, 1978b). Also, mycelium of $P$. cinnamomi was killed after 60 to $80 \mathrm{~min}$ at 39C and 5 to $7 \mathrm{~min}$ at 43C (Benson, 1978). However, mycelium within host tissue may not be as sensitive to thermal inactivation as these data suggest. Benson (1978) reported that immersion of infected Fraser fir roots in $45 \mathrm{C}$ water baths in- activated recent, but not older, infections. Furthermore, in large containers, temperatures in the center of the root zone may never reach levels injurious to Phytophthora (Fig. 6). Inoculum could survive in protected parts of the root zone and, with irrigation, move to areas where roots are heat-stressed and predisposed to infection.

The temperatures used in these experiments accurately reflect those encountered by roots in sun-exposed containers under typical summer conditions (Fretz, 1971; Keever and Cobb, 1985; Verma, 1979; Young and Hammett, 1980) (Fig. 6). It should be noted, however, that these experiments used single-episode heat treatments. In a nursery, roots in exposed containers are subjected to daily episodes of heat stress. This could lead to some physiological hardening of roots, making them somewhat less sensitive to the effects of high temperature. Also, in commercial nurseries, only plants on the perimeter of blocks are exposed to the low sun angles that cause the. greatest root heating. Containers within blocks are shaded by adjacent containers and would have more constant, favorable root-zone temperatures. However, plants are constantly removed from nursery blocks for shipment, and previously shaded containers can be suddenly exposed to direct, low-angle sun. The experiments reported here indicate that heat stress could predispose unhardened roots to infection. Measures to prevent root heating, such as shading or irrigation (Fig. 6B), could be helpful if they do not introduce other forms of root stress (e.g, $\mathrm{O}_{2}$ stress). It is clear, however, that temperatures to which container-grown plants are routinely exposed have the potential to predispose them to severe phytophthora root rot.

\section{Literature Cited}

Barr, W. and H. Pellett. 1972. Effect of soil temperature on growth and development of some woody plants. J. Amer. Soc. Hort. Sci. 97:632-635.

Benson, D.M. 1978. Thermal inactivation of Phytophthora cinnamomi for control of Fraser fir root rot. Phytopathology 68:1373-1376.

Blaker, N.S. and J.D. MacDonald. 1981. Predisposing effects of soil moisture extremes on the susceptibility of rhododendron to phytophthora root and crown rot. Phytopathology 71:831-834.

Chamberlain, D.W. 1970. Temperature range inducing susceptibility to Phytophthora megasperma var. sojae in resistant soybeans. Phytopathology 60:293-294.

Chamberlain, D.W. and 3.W. Gerdemann. 1966. Heat-induced susceptibility of soybeans to Phytophthora megasperma var. sojae, Phytophthora cactorum, and Helminthosporium sativum. Phytopathology 56:70-73.

Filmer, C. L. R., J.D. MacDonald, J.L. Paul, and A.T. Leiser. 1986. Influence of air-filled porosity of container media on phytophthora root rot of toyon. HortScience 21:1010-1011.

Fretz, T.A. 1971. Influence of physical conditions on summer temperatures in nursery containers. HortScience 6:400-401.

Graves, W.R. and M.N. Dana. 1987. Root-zone temperature monitored at urban sites. HortScience 22:613-614.

Harris, R.W. 1967. Factors influencing root development of containergrown trees. Proc. Intl. Shade Tree Conf. 43:304-314.

Heritage, A.D. and J.M. Duniway. 1985. Influence of depleted oxygen supply on phytophthora root rot of safflower in nutrient solution, $p$. 199-202. In: C.A. Parker, A.D. Rovira, K.J. Moore, and P.T.W. Wong (eds.). Ecology and management of soilborne plant pathogens. Amer. Phytopathol. Sot., St. Paul, Minn.

Hine, R. B., C. Alaban, and H. Klemmer. 1964. Influence of soil temperature on root and heart rot of pineapple caused by Phytophthora cinnamomi and Phytophthora parasitic. Phytopathology 54:1287-1289.

Hine, R.B. and M. Aragaki. 1963. Influence of soil temperature on a 
crown rot disease of parsley caused by Phytophthora parasitic. Phytopathology 53:1113-1114.

Hoagland, D.R. and D.I. Arnon. 1950. The water-culture method for growing plants without soil. Calif. Agr. Expt. Sta. Circ. 347.

Ingram, D.L. and D. Buchanan. 1981. Measurement of direct heat injury of roots of three woody plants. HortScience 16:769-771.

Keever, G.J. and G.S. Cobb. 1985. Irrigation scheduling: Effects on container media and canopy temperatures and plant growth, p. 5861. In: B.L. James (ed.). Proc. SNA Res. Conf.: 30th Annu. Rpt. Southern Nurserymen's Assn., Nashville, Term.

MacDonald, J.D. 1982. Effect of salinity stress on the development of phytophthora root rot of chrysanthemum. Phytopathology 72:214219.

MacDonald, J.D. 1984. Salinity effects on the susceptibility of chrysanthemum roots to phytophthora cryptogea. Phytopathology 74:621624.

MacDonald, J.D. and J.M. Duniway. 1978a. Influence of the matric and osmotic components of water potential on zoospore discharge in Phytophthora. Phytopathology 68:751-757.

MacDonald, J.D. and J.M. Duniway. 1978b. Temperature and water stress effects on sporangium viability and zoospore discharge in Phytophthora cryptogea and P. megasperma. Phytopathology 68:14491455.

Matkin, O.A. and P.A. Chandler. 1957. The UC type soil mixes, p. 68-85. In: K.F. Baker (ed.). The U.C. system for producing healthy container-grown plants. Calif. Agr. Expt. Sta. Man. 23.

Mircetich, S.M. and M.E. Matheron. 1976. Phytophthora root and crown rot of cherry trees. Phytopathology 66:549-558.

Patil, S.S. and R.A. Young. 1960. The influence of temperature on development of Phytophthora parasitic root rot of fuchsia. Phytopathology 50:386-388.

Raison, J. K., J.A. Berry, P.A Armond, and C.S. Pike. 1980. Membrane properties in relation to the adaptation of plants to temperature stress, p. 261-273. In: N.C. Turner and P.J. Kramer (eds.). Adaptation of plants to water and high temperature stress. Wiley, New York.

SAS Institute, Inc. 1988. SAS/STAT user's guide, Release 6.03 edition. SAS Institute, Cary, N.C.

Swiecki, T.J. and J.D. MacDonald. 1988. Histology of chrysanthemum roots exposed to salinity and Phytophthora cryptogea. Can. J. Bet. 66:280-288.

Tennant, D. 1975. A test of a modified line intersect method of estimating root length. J. Ecol. 63:995-1001.

Tennant, D. 1976. Root growth of wheat. I. Early patterns of multiplication and extension of wheat roots including effects of levels of nitrogen, phosphorus and potassium. Austral. J. Agr. Res. 27:183196.

Verma, B.P. 1979. Container design for reducing root zone temperature, p. 179-182. In: B.L. James (ed.). Proc. SNA Res, Conf.: 24th Annu. Rpt. Southern Nurserymen's Assn., Nashville, Term.

Wilcox, W.F. and S.M. Mircetich. 1985. Effects of flooding duration on the development of phytophthora root and crown rots of cherry. Phytopathology 75:1451-1455.

Wong, T. L., R.W. Harris, and R.E. Fissell. 1971. Influence of high soil temperatures on five woody-plant species. J. Amer. Soc. Hort. Sci. 96:80-83.

Young, K. and K.R.W. Hammett. 1980. Temperature patterns in exposed black polyethylene plant containers. Agr. Meteorol. 21:165172. 